\title{
Gender, Relationship Status, and COVID-19
}

Samantha Bates

College of Social Work, The Ohio State University

\section{Author Note}

I have no known conflicts of interest to disclose.

Correspondence concerning this article should be addressed to Samantha Bates, The Ohio State University, 1947 N College Rd College of Social Work Columbus, OH 43210. Email: bates.485@osu.edu 


\begin{abstract}
This article is a personal reflection about being a single woman in academia during the COVID19 pandemic. I describe how the pandemic has influenced my mental health and well-being and my feelings of connectedness to my institution, colleagues, and students. I discuss how gender, relationship status, and singlism may have influenced the social support and workload of single female faculty during the pandemic, and the need to explore these phenomena more intentionally to support and retain diverse women in the academy. By tying research examples to my personal experience, I hope to inform a conversation about how institutions can be more inclusive and intentional about challenging inequities associated with gender, relationship status, and singlism, along with combating social isolation and supporting better work-life balance for female faculty members who are not partnered and do not have children.
\end{abstract}

Keywords: female faculty, women, singlism, higher education, academia, pandemic 


\section{Gender, Relationship Status, and COVID-19}

I told myself, "I can do this. I'll enjoy the summer at home and ensure my teaching and research remain on track." A few weeks later, I realized I was starved of interaction, exhausted, and feeling unwell. Sound familiar? I knew as a scholar in a health science profession that the underlying cause of my exhaustion was connected to a lineage of research on loneliness. A team of researchers at the University of Chicago has made the connection between loneliness and health abundantly clear. To demonstrate their findings, imagine sending people out into the preCOVID world wearing a heart rate monitor that beeps to cue them to record two things. First, to record how lonely or connected they felt. Second, to record their current heart rate on the monitor. Then, imagine on the second day asking them to do the same thing, but also measuring their cortisol levels. Cortisol is the hormone used to measure our stress response. Researchers were trying to understand how stressful it is to be lonely (example adapted from Hari, 2018).

Scholars conducted this scenario pre-COVID-19 to demonstrate the important link between loneliness and well-being. Cacioppo et al. (2006) found that feeling lonely causes cortisol levels to surge. Don't get me wrong, cortisol is central to survival. If a bear is chasing you, you want your cortisol levels to increase and give you the energy to avoid the threat, to fight, or to run away. However, similar to being chased by a bear, prolonged loneliness sends our bodies into a fight, flight, or freeze response. In response to a lack of social interaction and a heightened awareness of our susceptibility to threats, we begin to feel less safe because we know no one is looking out for us. Our bodies become hyper-vigilant and more sensitive to threats, making us more suspicious and fearful of social interaction. Unfortunately, this stress response causes individuals experiencing prolonged bouts of loneliness to progress further into disconnection (Hari, 2018). Researchers have emphasized that acute loneliness is as stressful as a 
physical attack. Other scholars have attributed the effects of loneliness to increased odds of catching the common cold (i.e., poor immune response), increased risks for developing symptoms of depression, and increased risks for poor quality sleep (Hari, 2018). Knowing this, I asked myself: Could loneliness be the cause of my exhaustion during the pandemic?

Insert these findings from studies on loneliness into the time of COVID-19 and we could perhaps argue that loneliness is one of the culprits responsible for my declining health and wellbeing. Sitting in an empty house alone all day often made me, a single White woman on the tenure track, feel completely disconnected from my work, my students, my colleagues, and my community. Although I did not share the challenge of childcare or worry about a partner contracting COVID-19, I felt ostracized and disconnected from my colleagues, community, and institution. What no one saw behind the Zoom screen was the burdens I was carrying, of concerns about my health, the mental health concerns of my students, my financial responsibilities, and my fears of getting sick - alone.

I believe my experience is not unique, but may be lost in the conversations on the effects of COVID-19 on female faculty. To date, a majority of scholarship exploring the effects of the pandemic on faculty has focused on academic women with children. However, as I reflected on my own experience, I identified gaps in the research on the experiences of single female faculty during the pandemic. Loneliness, gender, relationship status, tenure and promotion, and worklife balance in higher education are relatively understudied, and have only recently begun to be discussed in relation to the COVID-19 pandemic. Gao and Sai (2020) discussed how single women living alone in the UK during the lockdown experienced a blur of boundaries between work and home. I completely understood and identified with this sentiment, the moment I read about their experience. When to work and when not to work - where to work and how to balance 
the pandemic with self-care, was challenging for me and other single women in the academy (Gao \& Sai, 2020; Utoft, 2020).

I also experienced a gendered and privileged sense of guilt for feeling so disconnected and rationalized further isolation by engaging in harmful self-talk: "I'm sure everyone is busy" and "I probably have it better than others" were the thoughts swirling through my head, as my well-being took a dive. Throughout the pandemic, I couldn't shake the emptiness I felt when approaching my job - something I've always felt deeply connected to. While scholars have found virtual workers facing challenges of isolation and loneliness (Bartel et al., 2012), how these feelings manifest themselves in our workload and in academia among single female faculty remains relatively unknown. I also noticed I was being asked to do more with less support, time, and direction, coupled with a glaringly evident expectation to provide social support to others (students, collaborators, friends, and family members). I kept thinking, is my experience unique?

Recent articles by Gao and Sai (2020) and Utoft (2020) are a few of the scholarly publications I found that explored challenges at the intersection of gender and relationship status during the COVID-19 pandemic. As a result of what I perceived as a gap in the narrative surrounding the experiences of women during the pandemic, I felt inclined to share my personal experience here, in an attempt to articulate the experiences of women, like myself, in academia. I hope to provide a gendered analysis and counter-argument to emerging narratives that posit single faculty members as "ideal academics," with opportunities to be highly productive despite living and working alone through a global pandemic. Moreover, although I am just one tenuretrack faculty member, I wrote this article to advocate greater exploration of the intersectional experiences of women in the academy with respect to gender, relationship status, productivity, mental health, and the COVID-19 pandemic. I argue here that if single women are positioned as 
the "ideal academics" during a time when their social supports have disappeared, we run the risk of further reinforcing a gender structure that tells women they must compromise relationships and over-commit to their work, in order to achieve success - a narrative supported and reinforced by statistics on single tenure-track women in academia.

\section{The Gendered Subculture of Academia}

To many of us, it is not surprising that an underlying gender substructure reinforces current inequities and rates of hiring, tenure, and promotion in academia. To fully frame how higher education reinforces inequity and how our gendered subculture influences the experiences of single women, I begin with some statistics at the intersection of gender, relationship status, family structure, and rates of tenure and promotion. Then, I describe through my own story how our history and current gendered subculture may have reinforced inequities and reshaped the workload of single female faculty members during the COVID-19 pandemic.

To date, women remain under-represented in tenure-track positions, but over-represented among adjuncts and non-tenure track faculty (Rivera, 2017) - a pattern that parallels dominant patterns in the gendered division of labor. On the basis of gender, Mason and Goulden (2004) found male faculty more likely to achieve tenure than female faculty with children and single female faculty without children. In terms of relationship status and family structure, academic men are more likely than academic women to be married and to have more children (Nakhaie, 2007; Probert, 2005). Further, in the context of men being more likely to be married, studies show married academics to be more productive than single ones (Wolf-Wendel et al., 2004). Studies also indicate tenure-track female faculty members as more likely to be single women without children than tenure-track male faculty members (i.e., Baker, 2008; also see $28 \%$ compared to $11 \%$ respectively in Mason \& Goulden, 2004). Hence, at the structural level, there 
are more single women in academia than men. In addition, male academics, irrespective of family structure, and married academics experience institutional privileges in relation to tenure progression, compared to their single female counterparts.

The aforementioned statistics point to the gender-family effects that are partly responsible for lower tenure rates among women and the way academic success is inter-related to gender, relationships, and family structure. Further, studies show tenure-track female faculty who delay having children or remain single have slightly higher tenure rates than women who had children within five years of obtaining their Ph.D. (Mason \& Goulden, 2004). Therefore, we must contend that women with children are the most vulnerable to the gender-family effects that persist in academia. However, scholars argue that while organizational norms cause single women to work harder and perhaps delay fertility to achieve success, the gendered division of labor too perhaps causes women to drop out of the race for tenure (Baker, 2008).

Based on previous findings, academia inextricably reinforces the gender structure of the dominant culture. Women are working harder to achieve the same success as men and remain responsible for family caregiving. For some, the pandemic was thought to create a more level playing field for all single male and female academics. Several of my own experiences during the pandemic made me reflect on my social identity as a White, single female academic, and how I perceived academia to conform to traditional gendered expectations and thereby artificially constrain women's careers. I began to think about my own experience and identify research that, from my perspective, is important to discuss the intersection of gender, relationship status, and the COVID-19 pandemic.

Gender, Relationship Status, and COVID-19 
During the COVID-19 pandemic, I spent countless hours alone in my home office contemplating the following: "Why am I exhausted? Why do I feel like the needs of my colleagues are recognized and supported, but not my own? Why is my service feeling more and more fragmented? Why am I spending increasingly longer time mentoring and meeting with distressed students?" Based on past research, these questions have been asked but not contextualized within the COVID-19 pandemic for single women in academia.

Tenure and promotion. In the introduction, I spoke about an underlying cause of my exhaustion and disconnection - loneliness. In my career thus far, I've learned that despair and loneliness often creep in when there are major disconnects between effort and reward, whether institutionally or interpersonally. With several months to reflect on this experience, I began to identify how our cultural and institutional norms during the pandemic impacted me as a single female faculty member. Institutionally, I felt irrelevant, with no connection between effort and reward, by which I do not mean fiscal or tangible rewards. A lot of the rhetoric from my university revolved around tenure extensions for the work not being done, but I wondered, "What about the work that was being done"?

I could see my colleagues and I exerting more emotional labor and making important adjustments to our research plans and pedagogical practices in real time. It felt like the benchmark remained the same, despite the landscape of academia changing drastically. Early in the pandemic, my institution offered us the option to taking a year "off" from our progress toward tenure. During this time, I contemplated the extension, but learned I might be taking a major risk if I pursued a clock extension. My colleagues and I talked about the apparent recession at our university. Many of us agreed that if you took the extension, you may get that year back, but be operating within an under-resourced budget coupled with the possibility of 
more students, greater teaching expectations, and more service. At the time, my university had accepted an additional 1,000 students and cut the overall operating budget by approximately $8 \%$ to $20 \%$ across some departments.

Additionally, delaying tenure advancement has financial implications and the potential to reinforce power inequities on the basis of gender. Financially, I shoulder my student loan debt and cost of living by myself. If women, with or without children, already earn less than men in higher education and disproportionately take clock-extensions, this strategy has the potential for academia to further reinforce pay inequities between men and women. In addition, tenure grants academics more protection and academic freedom to pursue new ideas, concepts, and research topics. If women delay tenure progression at a higher rate, this is disproportionately advantageous to academic men, granting them access to advancements that hold greater power, privileges, and decision-making positions in academia. From my perspective, my exhaustion and frustration were fueled by the concern that my institution would not do more than simply offer tenure-clock extensions to female faculty, further disadvantaging women in academia.

Teaching expectations. I also felt the expectations to perform in the classroom were actually heightened for women without children during the pandemic. A majority of communication outputs from my institutions and leaders focused on supporting faculty with children - undoubtedly an important population to support during the pandemic. Students at our university were privy to these emails as well. This communication, I believe, increased our empathy and awareness for the role of caregiving and working from home during the pandemic. However, I couldn't help but feel that single women in academics were reverted to a time where if you weren't solely responsible for raising children, then you were expected to give unconditionally to the future of "our children." This gendered phenomenon is rooted in our 
history of devaluation and subordination of women in the workplace, especially those employed in teaching positions.

Historically, until the late 1950's, single women shouldered the responsibilities of teaching in our schools. At this time, marriage bars existed in U.S. school systems prohibiting some married women from occupying teaching positions (Dwyer, 2006). Married women with children were thought to be unable to effectively work and raise a family simultaneously, resulting in single women disproportionately serving in teaching roles, where they were paid less and their skills highly devalued. I recognized the messages coming from my university made me feel more responsible for delivering high quality courses since current events and historic rhetoric reinforced the notion I was more available and able to do so. Furthermore, as a female instructor, I am already aware of the advantages that men hold in the academic classroom. For instance, Kardia and Wright (2004) contend that students express a higher tolerance for bad teaching and undesirable characteristics among male faculty, resulting in greater consequences and higher expectations of female faculty in the classroom. Studies show female professors must do more to earn credibility in the classroom (Kardia \& Wright, 2004).

Now, contextualize this research to COVID-19. If men are given more grace in the classroom and now we more fully empathize with faculty with children, where does that leave me? In retrospect, I felt an immense pressure to ensure my classes were up to par, partly due to the existing gender norms and also not having children to care for at home. In reality, I was learning an entirely new skill set with teaching shifted to online platforms. I was also grieving the loss of ability to reach and teach students in-person, a major social outlet for me as a single woman. Together, these factors made me spend more time preparing for online courses and less time balancing other responsibilities such as research and service. 
Student disclosures. I also noticed that external pressures that informed my commitment to teaching at the intersection of gender and relationship status made me more open to student disclosures of stress or trauma. Students would schedule meetings with me to talk about assignments that were layered in disclosures of stress and trauma. I was referring students to online mental health services at our university and concerned about the increased demand. This experience aligns with research on traditional gender roles that portray female faculty members as more open to disclosure, because of perceptions that women are more likely to offer social support, to be more caring, and to express concern for students (Hayes-Smith, Richards, \& Branch, 2010). While I was teaching last year, I noticed a higher frequency of students in online spaces would disclose confidential and concerning information about their mental health to me and several mentioned they thought I would be able to relate because I lived alone. Cummins (2005) argued prior to the pandemic that in the absence of partners and children, single childless female academics are asked to perform more caring tasks than their colleagues, making them feel even more taxed when approaching their research, and struggling to balance their social and work lives. I felt student disclosures played a large role in my feelings of exhaustion and further disconnection from my work.

In addition, in the classroom we were coping with two pandemics: the COVID-19 virus and structural racism. Since my courses are focused on social justice, students were showing up in need of the time and space to process the vicarious traumas assailing them through their televisions and social media. I also had a highly privileged subgroup of students who "didn't understand" why we needed to take class time to engage in critical conversations about race, police brutality, compassion, and policy. Even through Zoom, emotions were heightened and without the opportunity to cultivate in-person connections and psychological safety, I was 
constantly battling with how to show up as an effective instructor and I am a White woman. I cannot begin to imagine how the pandemics influenced faculty of color who, prior to the pandemic, are disproportionately called upon to do diversity work and mentoring (Wood, Hilton, \& Nevarez, 2015). I can only speak for myself and I felt an immense sense of responsibility to provide space and time for discussion, but also pressure to ensure micro-aggressions and further harm were not present in our online classrooms.

From an organizational perspective, female professors experience a higher prevalence of traumatic disclosures from students (Hayes-Smith et al., 2010). In turn, these experiences in academia can negatively impact female faculty across domains of teaching, health, well-being, and advancement. We must also consider that female faculty face additional external and organizational stressors, such as caregiving responsibilities, childcare, performance-based demands, the pressure to secure and maintain grants, and a highly competitive academic job market, thus limiting their ability themselves to seek support. For me, I felt a greater role strain than I had ever felt as an instructor. I know my body and mind carried this weight throughout the pandemic, further affecting my productivity and well-being adversely.

Work-life balance, singlism, and social support. We must also talk about work-life balance, singlism, and social support for female faculty during the pandemic. Prior to the pandemic, some scholars argued that rather than institutions working to dismantle gendered policies and practices, we are instead seeing a new socialization whereby single female faculty members are working harder to close gender gaps in academia. Indeed, in a survey of selfreported hours spent per week engaged in professional work, housework, and caregiving among academic faculty, women with children spent substantially more time engaged in housework and caregiving than men with children, women without children, and men without children (Mason 
\& Goulden, 2004). In contrast, women without children spent the most time engaged in professional work across all subgroups. Further, in a recent study on work-life balance, Denson and Szelenyi (2020) found single faculty without children reporting lower work-life balance than married and partnered faculty.

Researchers have advocated a phenomenon known as "singlism" as possibly contributing partially to the lack of work-life balance experienced by single female faculty. DePaulo and Morris (2006) refer to singlism as the expectation that single women who do not have children have more time and fewer life responsibilities - resulting in the perception among colleagues that they can be more committed to their jobs. Mason et al. (2013) posited that assumptions associated with singlism snowball into excuses for single faculty members to be saddled with more work, service, or tasks that are more time-intensive (i.e., job searches). This happens when faculty members with children or families are unable to commit (and for good reason) because of their work-home responsibilities. Instead of leaders and institutional policies, processes, or procedures that assess the workload of all faculty members, subjective opinions of workload, latent messages of commitment, and the "need to get this done" subtly move the work in the direction of faculty with perceived time and energy.

I noticed my service was becoming more and more fragmented. I was attending more meetings focused on teaching and advising. Chrisler (1998) found women academics more likely to be associated with committees that deal with student concerns, social issues, or routine matters, whereas male academics are likely to be on committees that deal with policy making or implementation, faculty status, or grievances. When I think about the service I performed during the pandemic, I was serving on committees more focused on teaching and student advising and organizing. I did not hold positions where leaders shared updates or adjustments that benefited 
my research or provided additional support for faculty. The excess commitment of female faculty and faculty of color, to institutional service roles, is a known gendered and racial institutional issue that likely exacerbated inequities during the pandemic (O’Meara et al., 2021).

I have also reflected on my role in accepting such service commitments. During the pandemic, I felt a sense of obligation to say "yes" and rationalized my excess commitments as being a good member of the team. I also noticed I was caring for others and making them feel better about my taking on more roles and responsibilities. I think this was related to both my relationship status and gender. I empathized with the stress of my female colleagues related to caregiving at home and wanted to be supportive, thereby feeling obligated to take on more responsibilities. Further, some research suggests that male academics find it easier to refuse work requests, including those relating to advising and social events (Baker, 2008). I certainly found it harder to say "no." I believe this is due in part to my socialization as a woman and the effects of benevolent sexism, whereby women's humility, charity, and hospitality are expected in the workplace, but also devalued when it comes to promotions and raises. These institutional, interpersonal, and internal experiences maintain the gendered subculture of academia, whereby women are serving excessively on committees and caring for students, with consequently less credit and time to publish, pursue grants, and collaborate with others.

I also want to mention the double bind. Women in the workplace, including those in academia, face a double bind whereby they are not only viewed as less competent and committed to their careers than men, but also penalized for violating prescriptive gender norms when viewed as assertive, achievement-directed, or career-oriented (Eagly \& Carli, 2007; Rivera, 2017). I think the interpersonal challenges faced by single women like myself during the pandemic align the double bind: the expectation was to be feminine, giving, open, warm, bubbly, 
and social. Meanwhile, gender norms also reinforced the notion that I should not be excessively career-focused or assertive (even if through silence and self-protection). During the pandemic, I found myself trying to prove my commitment to my colleagues and the institution and sacrificing the time and space to care for myself. I also couldn't find thesocial support I needed so much because no one in my department was experiencing the pandemic alone. My experience aligns with studies conducted prior to the pandemic that found single faculty members face challenges integrating into academic departments when activities or conversations are centered on the interests of married faculty and faculty with children (Mason etal., 2013). I noticed this was glaringly apparent during the pandemic. I felt shame in being unableto contribute to conversations about caregiving for children and of disclosing my sense of loneliness and disconnection.

Mental health and well-being. Lastly, as I mentioned in my introduction, I think it is important to note that conversations about the mental health and well-being of faculty were few and far between during the pandemic. Tenure-track professors shouldered much of the labor that kept our teaching and university afloat during the turbulent year. I noticed my tenure-track colleagues and I followed the lead of our institution, which was not to discuss our mental health or well-being. Instead, our conversations were replete with course redesign strategies, anxiety about the budget, faculty voicing their struggles about having children at home, and stress about job security. In my opinion, mental health became a catch-all for faculty. Whether explicitly communicated or not, the message was "everyone is in survival mode" and we never paused to check-in on the intersectional and diverse experiences of our fellow faculty members. In retrospect, the space for each of us to show up as our full selves didn't exist. If we strive to cultivate inclusive and productive academic institutions, there is more work to do in supporting 
faculty members' mental health and to combat loneliness should remote work continue into the future.

\section{Where Do We Go From Here?}

Given my experience and the literature suggesting progress toward tenure, workload, and well-being may be impacted by gender, relationship status, and COVD-19, I think there are opportunities to explore the experiences of single women during the pandemic, vis-a-vis their partnered colleagues and those with children. This article illustrates that there are multiple gendered processes, unconscious biases, and institutional norms interacting and reinforcing single women's workloads and advancement during the COVID-19 pandemic. Here, I offer a few thoughts to move the conversation forward towards how to support single women and other marginalized groups in academia after the COVID-19 pandemic.

First, the workloads of women in academia done during the pandemic need to be acknowledged beyond previous benchmarks related to progress towards tenure. O'Meara and colleagues recently stated, "One of the most important, but often overlooked, areas in which inequity can arise is within the distribution of faculty labor" (p. 1). The call to examine faculty labor during the pandemic, both explicit and implicit, is urgent given these factors are associated with productivity, satisfaction, and retention. A recent report on the Faculty Workload and Rewards Project (O’Meara et al., 2021) provides actions that academic units can take to examine and promote workload equity, especially for women and under-represented faculty members.

Scholars identified six conditions linked to equitable workloads: transparency, clarity, credit, norms, context, and accountability. Recommendations in the report provide examples of policies and practices that promote these six conditions. One such example is the Equity-Minded Faculty Workload Audit, an audit designed for academic leaders, department chairs, faculty 
workload commissions, and individual faculty members who want to reform faculty workloads with equity in mind (O’Meara et al., 2021). To move issues of equity forward, I recommend all institutional leaders and faculty members read this report. I see opportunities for this report to inform conversations that help to reform policies and practices that reinforce institutional sexism and assumptions associated with singlism. By giving leaders the tools to look at policy and practices that may result in women being under-resourced, excluded, or overworked, we may uncover multiple blind spots and better support our diverse and intersectional workforce.

During the pandemic, it is also likely that women shouldered a large responsibility of caring for students, teaching changes, and service focused on student support, all impacting their ability to conduct high-quality research and perform at or near pre-COVID benchmarks. I recommend that departments allow faculty to submit impact statements on their experiences during and after the pandemic. Statements should include the ways in which their time was reallocated and a section on the emotional labor exerted during the two pandemics: COVID-19 and our country's racial reckoning. This should not just be a one-time statement. It is possible the service commitments and diversity work demanded of single faculty, female faculty, and faculty of color during the two on-going pandemics will persist. Institutional leaders must be prepared to look holistically at the contributions made by diverse faculty members and also utilize these statements to deconstruct any racial or gendered inequities in workload.

We can also begin to reimage pathways toward tenure and promotion that acknowledge the various contributions of faculty from diverse backgrounds and their commitments to inclusion. Indiana University-Purdue University Indianapolis recently approved a new path to tenure and promotion centered on diversity, equity, and inclusion work. This pathway has the potential to more equitably acknowledge the labor of marginalized faculty members whose work 
in these areas is highly valuable to institutions across the country but may be less reflective in terms of grant awards and scholarly publications (Flaherty, 2021). I recommend the time for change is now given the effects of COVID-19 on productivity will probably impact female faculty and faculty of color for years to come.

Moreover, teaching innovations, adaptations, and challenges faced by female academics in the classroom should be appreciated and recognized beyond teaching evaluations. Women, like myself, possibly overcommitted to providing excellent course instruction while facing instructional challenges and exerting greater emotional labor in online classrooms causing a dip in their productivity outside the classroom. In the future, it is also clear institutions must do more to support faculty and students during crises like COVID-19. Faculty, especially female faculty and faculty of color, probably experienced numerous student disclosures due in part to universities lacking adequate prevention and intervention resources focused on student mental health and well-being. If we want diverse faculty to be successful in academia, we have a responsibility to create more prevention pathways within institutions and to destigmatize mental health for students. Faculty alone cannot hold the responsibilities of teaching, conducting research, and providing mental health supports for students in crisis.

Finally, disrupting the dominant gender structure will require both interpersonal and organizational shifts to support single female faculty in academia. We must continue to seek equity in academia that moves away from numerical equity and towards equity of experience and quality of life. Leaders should be privy to the ways in which single female faculty experience the workplace and, due in part to gender norms, may have more fragmented service, less access to serving on policy-making committees, and less social support. Denson and Szelenyi's (2020) recent study is one of the first to explore the relationship status and work-life balance in higher 
education and is an important step forward in helping academia retain and support single women. Their work shows that when colleagues as a whole feel that their institution supports work-life balance, it strengthens the positive association between individual perceptions of institutional support for work-life balance and perceived work-life balance. Work-life balance should be prioritized and more deliberately studied among single female faculty to inform policy and equitable workload distributions. I see opportunities for leaders and single women to advocate for affinity groups or cohort hires to increase their social support structures in academia.

Importantly, gender inequities, experiences of loneliness, and singlism in academia do not occur in a vacuum. The intersection of gender and relationship status played a role in how I experienced academics during the pandemic. My experiences align with the underlying gendered assumptions, beliefs, and preferences of organizational actors in dominant culture and academia that result in vast inequities in workload and a potential exacerbation of mental health risks. With women holding more and more faculty positions in higher education and our workspaces becoming more diverse in terms of relationship status, race, sexuality, age, and other social factors, we have our work cut out to ensure all faculty feel included and supported in their progression towards tenure. It should not be that single women who do not have children are viewed and socialized as "ideal academics" meanwhile their male counterparts continue to achieve tenure at higher rates. I hope that this personal narrative moves the conversation forward at the intersection of gender and relationship status and other more diverse demographic compositions (i.e., LGBTQIA+, faculty of color, nationality, able-bodied, etc.), given that we fought to be in academia and now need strategies to dismantle inequities and keep us here. 


\section{References}

Baker, M. (2008, July). The family life of academics: Gendered priorities and institutional constraints. In Annual Conference of the Australian Institute of Family Studies (pp. 9-11).

Bartel, C. A., Wrzesniewski, A., \& Wiesenfeld, B. M. (2012). Knowing where you stand: Physical isolation, perceived respect, and organizational identification among virtual employees. Organization Science, 23(3), 743- 757. https://doi.org/10.1287/orsc.1110.0661

Cacioppo, J. T., Hughes, M. E., Waite, L. J., Hawkley, L. C., \& Thisted, R. A. (2006). Loneliness as a specific risk factor for depressive symptoms: cross-sectional and longitudinal analyses. Psychology and Aging, 21(1), 140.

Chrisler, J. C., Herr, L., \& Murstein, N. K. (1998). Women as faculty leaders. Career strategies for women in academe: Arming Athena, 107-134.

Cummins, H. A. (2005, May). Mommy tracking single women in academia when they are not mommies. In Women's Studies International Forum, 28(2-3), 222-231.

Denson, N., \& Szelényi, K. (2020). Faculty perceptions of work-life balance: The role of marital/relationship and family status. Higher Education, 1-18.

DePaulo, B. M., \& Morris, W. L. (2006). The unrecognized stereotyping and discrimination against singles. Current Directions in Psychological Science, 15(5), 251-254.

Dwyer, D. (2006). Justice at last?: The temporary teachers club and the Teaching Service (Married Women) Act 1956. Labour History, (91), 151-168. doi:10.2307/27516157

Flaherty, C. (2021, May 14). The DEI pathway to promotion. Retrieved from https://www.insidehighered.com/news/2021/05/14/iupui-creates-path-promotion-andtenure-based-dei-work 
Gao, G., \& Sai, L. (2020). Towards a 'virtual' world: Social isolation and struggles during the COVID-19 pandemic as single women living alone. Gender, Work \& Organization.

Hari, J. (2020). Lost connections. Bloomsbury Publishing.

Hayes-Smith, R., Richards, T. N., \& Branch, K. A. (2010). 'But I'm not a counsellor': The nature of role strain experienced by female professors when a student discloses sexual assault and intimate partner violence. Enhancing Learning in the Social Sciences, 2(3), 124.

Kardia, D. B., \& Wright, M. C. (2004). Instructor identity: The impact of gender and race on faculty experiences with teaching. Occasional Paper. University of Michigan Center for Research on Learning and Teaching.

Mason, M. A., \& Goulden, M. (2004). Marriage and baby blues: Redefining gender equity in the academy. The Annals of the American Academy of Political and Social Science, 596(1), 86-103.

Mason, M. A., Wolfinger, N. H., \& Goulden, M. (2013). Do babies matter? Gender and family in the ivory tower. New Brunswick: Rutgers University Press.

Nakhaie, M. R. (2007). Universalism, ascription and academic rank: Canadian professors, 19872000. Canadian Review of Sociology, 44(3), 361-386.

O’Meara, K., Culpepper, D., Misra, J., \& Jaeger, A. Equity-minded faculty workloads: What we can and should do now. American Council on Education. Retrieved from https://www.acenet.edu/Documents/Equity-Minded-Faculty-Workloads.pdf

Probert, B. (2005). 'I just couldn’t fit it in': Gender and unequal outcomes in academic careers. Gender, Work \& Organization, 12(1), 50-72. 
Rivera, L. A. (2017). When two bodies are (not) a problem: Gender and relationship status discrimination in academic hiring. American Sociological Review, 82(6), 1111-1138.

Utoft, E. H. (2020). 'All the single ladies' as the ideal academic during times of COVID19?. Gender, Work \& Organization, 27(5), 778-787.

Wolf-Wendel, L., Twombly, S. B., \& Rice, S. (2004). The two-body problem: Dual-careercouple hiring practices in higher education. JHU Press.

Wood, J. L., Hilton, A. A., \& Nevarez, C. (2015). Faculty of color and White faculty: An analysis of service in colleges of education in the Arizona public university system. Journal of the Professoriate, 8(1), 85-109. 